International Journal of Business Management and Economic Review

Vol. 3, No. 06; 2020

ISSN: 2581-4664

\title{
THE RELATIONSHIP BETWEEN CONFLICT MANAGEMENT AND MEDICAL DOCTORS JOB PERFORMANCE IN TANZANIAN PUBLIC HOSPITALS
}

\author{
Ngirwa, C \\ Institute of Social Work \\ Jaensson, J-E., \\ Open University of Tanzania \\ Barongo, $\mathbf{F}$. \\ Mzumbe University \\ http://doi.org/10.35409/IJBMER.2020.3213
}

\begin{abstract}
The study investigated the relationship between conflict management and job performance of medical doctors in public hospitals in Tanzania andmore specifically, determining the relationship between conflict management and job performance of medical doctors in public hospitals in Tanzania. The study embraced a case study research design with a sample of 191 respondents that were selected using purposive and snowball sampling technique. A questionnaire was used to collect primary data at Muhimbili National Hospital and Dodoma Regional Referral Hospital as study areas. The collected data were analyzed using regression analysis techniques from 191 respondents whereby the response rate was $74.9 \%$ (143). The findings revealed that there is a significant positive relationship between conflict management and medical doctor's job performance and that effective conflict management enhances job performance. It was recommended that organizations should embark on training of employees on conflict management issues to equip them with relevant knowledge on how to manage conflict for job performance.
\end{abstract}

Keyword:conflict, conflict management and job performance

\section{INTRODUCTION}

Conflicts can be between people, organizations, nations, political parties, and other entities (Rahim, 2011). These conflicts can be as a result of scarce resources, status inconsistencies, incompatible goals and time horizons, overlapping authority, task interdependencies, incompatible evaluation or reward systems and many more other causes (Agwu, 2013). Recently, there have been renewed interest and significant changes in the study of conflict in social and organizational contexts. Individuals, groups and organizations experience conflict at some time or another as they affect business or cooperate with one another in the performance of work (Murerwa and Guantai, 2019). We need conflict for the functioning of the organization in general, whereby the main concern is the management of the magnitude of the conflict that brought about good performance. Managers in most of the organizations spend most of their 


\section{International Journal of Business Management and Economic Review}

Vol. 3, No. 06; 2020

ISSN: 2581-4664

considerable time dealing with conflicts and that how they manage them becomes increasingly crucial to the normal execution of their duties (Ojo and Abolade, 2014). The conflict could be viewed as a situation of competition in which the parties are aware of the incompatibility of potential future positions in which each party wishes to occupy a position that is incompatible with the wishes of the other (Ojo and Abolade, 2014).

Conflicts regularly arise as the outcome of competition of employees for available scarce resources as they are trying to manage the little they have (Abioroet al., 2019). Conflict in public hospitals and health centers between the government and medical doctors creates an unfavorable and unsupportive environment for the work to be performed and attain the desired performance (Isangula, 2012). Despite the fact that Tanzania has been marked as one of the peaceful countries in the World, she has been facing almost this type of conflicts (Kijo-Bisimba, 2012).

Management of conflict is extremely important for the functioning of organizations and for the personal, cultural and social development of human beings (Jaden, 2018). Constructive and creative conflict management is a real challenge and a goal of any professional who is genuinely interested in assisting others and the organization as a whole, in changing unfavorable conflict situations into positive, cooperative and relatively peaceful directions (Blank, 2020). This way of maintaining a reasonable number of conflicts, promotes motivation, enhances morale and promotes individuals and organizational growth (Al-Hamdanet al., 2011). In managing conflicts there are five styles which are integrating style (high concern for self and others), obliging style (low concern for self and high concern for others), dominating style (high concern for self and low concern for others) avoiding style (low concerns of self and others) and the compromising style (intermediate in concern for self and others) (Rahim, 2011). Managers should be able to develop various relevant conflict management styles, and it is recommended that they organize various trainings on conflict management regularly for the employees (Murerwa and Guantai, 2019).

The good performance of any work organization depends on its human resources (Ngirwa, 2006). Other studies, like Ali (2016); Ayub (2016); Jaden, 2018; Longe (2015); Ojo and Abolade (2014); Olang (2017); Saranya (2017) and Shaukatet al., (2017) focused much attention on the relationship between conflict management and job performance in other public and private sectors rather than health sector.

Job performance and conflicts of employees in an organization are highly predicted by personality traits and conflict management, it's the relationship between personality traits (agreeableness, neurotic and extroverts) and conflict management (Integrating, Obliging, Compromising, Dominating, and Avoiding styles) (Ayub, 2016; Saranya, 2016). If the conflict is well managed it will increase the performance of employees and that of the organization and vice versa of it is true (Ali, 2016). Employee's job performance and that of the organization is improved by employing relevant ways of managing conflicts (Awan and Saeed, 2015), although there are other factors (internal and external) that influence job performance in respective organizations, the study has confined itself into one factor which is conflict management as it 
International Journal of Business Management and Economic Review

Vol. 3, No. 06; 2020

ISSN: 2581-4664

influences job performance.

\section{LITERATURE REVIEW}

The concept of conflict

Conflict may be defined as "an interactive state in which the behaviors or goals of one actor are to some degree incompatible with the behavior or goals of some other actor or actors" (Rahim, 2011; p 15). It can as well be definedas "an interactive process manifested in incompatibility, disagreement, or dissonance within or between social entities (i.e., individual, group, organization, etc.)" (Rahim, 2001; p 18 and Rahim, 2011; p. 16). The disagreement can be because of the tasks performed, personal grudges or any other form of disagreement.

\section{Conflict Management}

Conflict management can be seen as various ways in which conflict can be controlled during and after it occurs. It may involve the interference or disruption by one person or group of persons, or in some way or ways which make another action less likely to be effective (Agwu, 2013; p. 34). It shouldn't be seen as avoidance, termination or reduction of conflict, but it is how the organization designs the best ways to minimize the negative effects of conflict. Ajikeet al., (2015; p. 264) define conflict management as "involving implementation of strategies to limit the negative aspects of conflict and to increase the positive aspects of conflict at a level equal to or higher than where the conflict is taking place.

\section{Job Performance}

This is about how well /bad a person or an employee does an assigned activity or job. Performance is often defined "simply in output terms - the achievement of quantified objectives and it's a matter not only of what people achieve, but how they achieve it" (Armstrong, 2006; p. 497).

Ojo and Abolade (2014; p. 130) define Performance as "a reward" while Shmailan (2016; p. 1) Defines performance as "what the organization hires one to do and do well". Also, job performance is the practical reflection of that employee's aptness to that profession, which makes the employer rejoice (Shaju and Subhashini, 2017).

Job performance and conflicts of employees in an organization is highly predicted by personality traits and conflict management styles, it's basically the relationship between personality traits (agreeableness, neurotic and extroverts) and conflict management styles (Integrating, Obliging, Compromising, Dominating, and Avoiding styles) (Ayub, 2016; Saranya, 2016). If the conflict is well managed it will increase the performance of employees and that of the organization and vice versa of it is true (Ali, 2016). Employee's job performance and that of the organization is improved by employing relevant ways of managing conflicts (Awan and Saeed, 2015). Job performance of an employee in the medical sector is measured under the four categories work quality, work quantity, work efficiency and standard working procedures (SOP's).

The employee's performance can be easily measured on the output produced. This means the quality of work that has been done determines the performance of the doer. Also, the number of items produced can be a determinant for an employee's performance in an organization. The 


\section{International Journal of Business Management and Economic Review}

Vol. 3, No. 06; 2020

ISSN: 2581-4664

issue of how many items produced measures the individual's performance to a great extent. In the work, efficiency is all about the balance between the quantity and quality of work done in an organization. The amount of resources used in the production of a certain quality product is what brings the balance between the two. On the SOP's is that the work of a medical doctor can also be measured using the standard operating procedures in every task that a medical doctor performs the process of attending a patient.

These are the procedures of a set of procedures for the performance of a certain act or a response to a certain incident. Lastly, the performance of an employee in and organization is determined by the performance of an organization in particular because there is no organization that performs without the commitment of its employees. As for this study; work quality, work quantity, work efficiency, and SOPs were used to measure the performance of medical doctors.

\section{Conflict Management Theory}

Conflict theory holds that social order is maintained by domination and power, rather than consensus and conformity (Rahim, 2011).

\section{The Contingency Theory of Conflict Management}

Management scholars agree that there is no best way to make decisions, to lead and to motivate employees of any organization (Rahim, 2011). Since its conceptual breakthrough in the late 1960s, the contingency perspective has become a significant theoretical perspective to study various aspects of management (Thai, 2014). Taking the lead from the contingency approach, it is doable to build up a contingency theory of conflict management as if a conflict situation is characterized by low decision quality and low acceptance. Then the dominating style is justified; where there are high decision quality and high decision acceptance, the integrating style will be appropriate; where there are low decision quality and high decision acceptance, the obliging style will be appropriate; Where there are high decision quality and low decision acceptance, then the avoiding style will be justified and finally, the compromising style indicates intermediate concern for decision quality and decision acceptance (Rahim, 2011).

The theory does not present the five model styles of managing conflict in an organization but rather it presents how a thorough analysis of the conflict situation can indicate an appropriate style of managing conflict in an organization. A study by Ndulue and Ekechukwu, (2016) on the impact of conflict management on employee performance of the Nigerian Breweries Company has recommended that the improvement should be in the area of conflict management approaches (bargaining, compromise, and forcing) since it improves employees' performance.

In a conflict situation where there are low decision quality and low acceptance, the avoiding style of handling interpersonal conflict may be justified. In the reverse condition where there is high decision quality and high acceptance using the integrating style is the most appropriate to use. In a situation where there are low decision quality and high acceptance, then the obliging style is appropriate and where there are high decision quality and low acceptance, then the dominating style is appropriate and lastly, where there is an intermediate concern for decision quality and acceptance then the compromising style is appropriate. 


\section{International Journal of Business Management and Economic Review}

Vol. 3, No. 06; 2020

ISSN: 2581-4664

The theory shows that there is no best style for dealing with different situations, whether a particular conflict management style is appropriate or inappropriate depends on the situation. This study is guided by the contingency theory of conflict management.

In a contingency theory, an organization as an open system that need careful management to satisfy and balance internal needs and to adapt to environmental circumstances would require a stable and consistent or accurate person who would be able to scan the internal and external environment carefully and suggest an appropriate approach of managing conflict or rather the opposite of that it will be disastrous to the functioning of the organization.

It can be concluded that there is 'no one best way' or approach in the management of conflicts in organizations or doing things, the different situation calls for a different approach to handle, manage, and solve the arising conflicts. Organizations are Open systems, which allow interactions with outsiders and also allow challenges every now and then, which require 'adaptable' and 'situational' solutions in order to manage them or issue concerned.

\subsection{Empirical Literature}

Different studies by Agwu (2013); Chigozie (2017); Hossain (2017); Jaden (2018); Ogaga (2017); Ojo and Abolade (2014); and Pitsillidou et al. (2018) revealed that there is a significant relationship between conflict management and job performance and that revives the inner drives to enable employees work in the attainment of organisational objectives.

\section{METHODOLOGY}

A quantitative research design was used and data were collected using questionnaires from two public hospitals, which are Muhimbili national hospital and Dodoma referral regional hospital. A list of medical doctors present during the strike was provided to the researcher by the hospital administrations (165 from Muhimbili and 26 from Dodoma) and therefore the sample of the study included all 191 medical doctors from the study area who were present before year 2012 and a total of 143 medical doctors responded to the distributed questionnaires which is $74.9 \%$ response rate.

\section{RESULTS AND DISCUSSION}

The study aimed at identifying the relationship between conflict management and medical doctor's job performance in public hospitals. The assumption was that the understanding of the relationship between conflict management and medical doctor's job performed in public hospitals would enhancethe theoretical contribution to the cause and effect between the two variables of conflict management and job performance in the health sector.

Regression analysis was performed to institute the relationship between conflict management style and job performance of medical doctors in public hospitals. The main purpose was to determine the degree to which conflict management styles influence job performance. Thestudy of the relationship between conflict management and job performance is almost a new study in Tanzania and there are some controversial feelings about if the two variables relate to one 


\section{International Journal of Business Management and Economic Review}

Vol. 3, No. 06; 2020

ISSN: 2581-4664

another in the sense that one variable affects or influence the other. Different studies by different scholars confirmed the strong relationship between the two variables. A study by Agwu, (2013) revealed that there is a significant relationship between conflict management styles and employees' job performance; another study by Ojo and Abolade, (2014) revealed that organization's conflict management style influences employee performance in the organization.

In his study Hossain, (2017) revealed that there is a considerable relationship between organizational conflict and employee performance and that conflict management styles should be highly utilized to bring conflicts to normal for employee's performance. In relation to the study objective, this research focused on finding out whether conflict management is directly related to job performance bearing in mind the Tanzanian health sector system and the environment in general.

Outcomes are shown as follows.

Table 4.1: Model Summary

\begin{tabular}{|l|l|l|l|l|}
\hline Model 1 & R & R Square & Adjusted R Square & Std. Error of the Estimate \\
\hline & $.804^{\mathrm{a}}$ & .646 & .641 & 2.62441 \\
\hline
\end{tabular}

a. Predictors: (Constant), Conflict Management (CM)

b. Dependent Variable: Medical Doctors Job Performance (MDJP)

In the model summary (Table 4.1), $\mathrm{R}$-square is 0.646 suggesting that $64.6 \%$ of the variability in job performance can be elucidated by these variables (Conflict management). This determination of the coefficient (R-square) designates that there is a viable positive relationship between the two variables (Conflict management and job performance) of the study and that conflict management influence medical doctor's job performance positively by $64.6 \%$. This indicates that the remaining percentage to reach $100 \%$ is covered by other factors. In this regard the suggested regression model is

$\begin{array}{cll}\mathbf{Y}=\boldsymbol{\beta 0}+\boldsymbol{\beta 1 X 1}+\mathbf{e} & & \\ \text { Whereby; Y } & = & \text { Dependent variable (Job Performance) } \\ \beta \mathrm{O} & = & \text { constant } \\ \beta 1 \mathrm{X} 1 & = & \text { Conflict management } \\ \mathrm{e} & = & \text { error term }\end{array}$

Table 4.2: Coefficients 


\section{International Journal of Business Management and Economic Review}

Vol. 3, No. 06; 2020

ISSN: 2581-4664

\begin{tabular}{|llllll|}
\hline & \multicolumn{2}{c|}{$\begin{array}{l}\text { Unstandardized } \\
\text { Coefficients }\end{array}$} & \multicolumn{2}{l}{$\begin{array}{l}\text { Standardized } \\
\text { Coefficients }\end{array}$} \\
Model 1 & B & $\begin{array}{l}\text { Std. } \\
\text { Error }\end{array}$ & Beta & t & Sig. \\
\hline (Constant) & .563 & 3.117 & & -1.300 & .196 \\
Conflict Management & .544 & .035 & .792 & 15.385 & .000 \\
\hline \multicolumn{7}{l}{ a. Dependent Variable: Medical Doctors Job Performance } \\
\hline
\end{tabular}

Table 4.2 indicates the conflict management has a significant level of 0.000 while the recommended Alpha $(\alpha)$ is not exceeding 0.05 with an unstandardized coefficient of 0.544 and a standardized coefficient of 0.792 . Basing on the above explanations, it can be deduced that there is a positive significant influence of conflict management on job performance in public hospitals. In general, the regression analysis outcomes have revealed that conflict management has a significant influence on medical doctor's job performance. However, it's not the only factor affecting medical doctors' job performance in public hospitals.

These findings, results are confirmed by other previous studies, like Agwu (2013) that revealed a significant relationship exists between conflict management and employees' job performance and no differences exist between managerial and non-managerial employees 'perception of the effectiveness of conflict management strategies. Ajike et al. (2015) confirms the existence of the relationship between conflict management and job performance of employees. Chigozie (2017) also confirms the significant relationship between the variables that exist in organizations.

Another study by Ogaga (2017) informed that conflict has a significant relationship on the performance of employees. Other studies by Ayub et al. (2016); Isangula (2012); Kazimoto (2013); Longe (2015); Furumo (2008); Saranya (2016); Hossain (2017); Ojo and Abolade (2014); Olang (2017) and Wanjau et al. (2012) who generally found out that the magnitude of the conflict existing in different workplaces has a great influence on the employee's performance. Lastly, a study by Jaden, (2018) suggested the use of compromising style, avoiding style, and dominating style in managing conflicts in public hospitals. It can, therefore, be deduced from the study findings that conflict management influences the medical doctor's job performance in public hospitals.

Deducing from the study quantitative findings, it was generally noted that the conflict management influence medical doctor's job performance in public hospitals. It could have been thought that the relationship could be obvious as long as the two sides of variables relate to one another and it is like this everywhere and every time. This is not right; the important factor to note here is that each sector has its own needs basing on the type of jobs performed, the nature of the organization and its culture. The nature of the job, the nature of the organization, and organizational culture of the health sector are different from other sectors and thus the 
International Journal of Business Management and Economic Review

Vol. 3, No. 06; 2020

ISSN: 2581-4664

relationship between the variables was important to be done.

\section{CONCLUSION AND RECOMMENDATION}

Generally, the relevant authorities should ensure that all factors and demands necessitated or that pushed the parties to enter into conflict are worked upon. This does not mean that the government has to accept all the demands as one could think, but discuss them together with medical doctors would enhance the general understanding of the general conflict and enable the parties to come to a mutual conclusion. On the other end the government through its ministry of health, community development, gender, elderly and children (MoHCDEC) should ensure that citizens receive proper healthcare and contribute effectively to the development of the country.

\subsection{Recommendations and policy implications}

Thestudy complements to the body of knowledge that there is a significant relationship between conflict management and medical doctor's job performance. The study findings indicate that there are other factors influencing the relationship between the variables, but significantly employee's job performance is affected by conflict management style in an organization. From the study findings, the organization should put more effort into employee training in conflict management areas so as to enable them to create a conducive working environment.

Theoretically, the study contributes and adds more inputs. The findings of the study add a new perspective on the underlying assumptions of the contingency theory of conflict management that management of conflicts and especially in public hospitals in developing countries would require considerations of medical doctor's perception and job commitment as all these increases the work morale and finally contribute to the job performance of medical doctors. The general assumption of the theory is that once conflicts at workplaces have been managed they increase employee's job performance. This assumption neglects the medical doctor's perception and commitment aspect of their jobs; sometimes employees are performing, but not committed and even their positive perception is questionable. In order for the medical doctors to have a consistent job performance, these aspects of performance improvement (perception and commitment) should be taken into consideration. The theory is silent about these aspects of job performance and their contribution toward a sustainable medical doctor's job performance. Managing conflicts do not only end at analyzing a conflict situation and proposing relevant conflict managing styles, but it has to go further ensuring sustainability of job performance and that has to include medical doctor's perception of the whole conflict situation and their job commitment.

The study findings suggest that apart from studying a conflict situationthoroughly to suggest a relevant conflict management approach but also considering the medical doctor's ability to form a generalized perception concerning the extent to which the government valued their contributions and cared about their well-being was important and hence the perceived organizational support theory.

\section{REFERENCES}

Abioro, A. M., Odunlami, A. S., and Ekpudu, E. J., (2019). Conflicts Management Strategies: A Tool for Industrial Harmony. Izvestiya Journal of Varna University of Economics. 63(1), 


\section{International Journal of Business Management and Economic Review}

Vol. 3, No. 06; 2020

ISSN: 2581-4664

19-34.

Agwu, M. O., (2013). Conflict management and employee performance in Julius Berger Nigeria Plc. Journal of Human Resources Management and Labor Studies.Bonny Island. 1(1), 3445.

Ajike, E. O., Akinlabi, B. H., Magaji, N., \&Sonubi, A. O., (2015).Effect of Conflict Management on the performance of financial service organization. In Nigeria: An Empirical Study of Access Bank Plc. International Journal of Economics, Commerce and Management. 3(7), 260-272

Ali, M., (2016). The role of conflict management in organizational performance Case Study: Somali National University. High-quality Research Support program (HQRS).

Al-Hamdan, Z., Shukri, R., and Anthony, D. (2011).Conflict management styles used by nurse managers in the Sultanate of Oman. Clinical Nursing, 20, 71-580.

Anangisye, W. A. L., (2010). Promoting teacher ethics in colleges of teacher education in Tanzania: practices and challenges. African Journal of Teacher Education, 1(1), $64-77$.

Armstrong, M., (2006). Human Resource Management Practice., (10th edition). London. Kogan Page Limited.

Blank, S. (2020). Managing Organizational Conflict. North Carolina. McFarland \& Company, Inc

Chigozie, N. E., (2017). Impact of Organizational Conflict on Employee Job Performance in Selected Hotels (in Lagos Nigeria). TURIZAM, 21(1), 45-64.

Creswell, J. W. (2009). Research design: Qualitative, quantitative, and methods approach. (3rd edition). California: Sage Publications Ltd.

Creswell, J. W. (2014), Research design qualitative, quantitative and mixed methods approach, (4th edition). Los Angeles: SAGE Publications, Inc.

Dunnette, M. D. (1998). The handbook of industrial and organizational psychology, (2nd edition). California: Davies-Black Publishing.

Ebtesam, S. A. A., Aya G. H. G. (2018). The Effect of Conflict Management Program on Quality of Patient Care.American Journal of Nursing Science. 7( 5), 192-201.

Eisenberger, R., Huntington, R., Hutchison, S. \& Sowa, D. (1986).Perceived organizational support. Journal of Applied Psychology, 71 (3), 500-507.

Furumo. (2008). The impact of conflict and conflict management style on deadbeats and deserters in virtual teams. Hawaii International Conference on System Sciences, 1-10.

Gull, S., Rehman, H., and Zaidi, S.F.B., (2012). Impact of conflict management styles on team effectiveness in the textile sector of Pakistan. International Journal of Business and Management, 7(3), 219-229.

Hossain, Z, (2017). The impact of organizational conflict on employees' performance in private commercial banks of Bangladesh. Journal of Business and Management, 19(10), 12-21

Isangula, K. G. (2012). Activism during doctor's strike in Tanzania, success and Setbacks, Sikika Journal. 